Le point sur...

\title{
Chili : un système éducatif contesté
}

\section{Bernadette Plumelle}

\section{(2) OpenEdition}

\section{Journals}

Édition électronique

URL : http://journals.openedition.org/ries/246

DOI : $10.4000 /$ ries.246

ISSN : 2261-4265

Éditeur

Centre international d'études pédagogiques

Édition imprimée

Date de publication : 1 décembre 2006

Pagination : $12-13$

ISSN : 1254-4590

Référence électronique

Bernadette Plumelle, «Chili : un système éducatif contesté », Revue internationale d'éducation de Sèvres [En ligne], 43 | décembre 2006, mis en ligne le 23 juin 2011, consulté le 14 novembre 2019. URL : http://journals.openedition.org/ries/246 ; DOI : 10.4000/ries.246

Ce document a été généré automatiquement le 14 novembre 2019.

(c) Tous droits réservés 


\title{
Chili : un système éducatif contesté
}

\author{
Bernadette Plumelle
}

1 Quelques mois après son arrivée au pouvoir, la présidente du Chili, Michelle Bachelet, a fait face à une révolte étudiante sans précédent. Le mouvement de contestation lancé par les lycéens s'est étendu ensuite aux étudiants et aux professeurs pour réclamer une réforme de l'enseignement. En réponse à cette protestation massive de milliers de grévistes, Michelle Bachelet a annoncé un ensemble de mesures et s'est engagée à déposer un projet de loi pour réformer la Constitution et «consacrer le droit de tout citoyen à une éducation de qualité ». Or une grande partie des critiques exprimées par les différentes catégories de protestataires (lycéens, étudiants, enseignants) prennent leurs racines dans une réforme éducative lancée sous le régime de dictature d'Augusto Pinochet en 1982.

\section{Un système éducatif très contesté : retour sur les vingt dernières années}

2 Une réforme éducative de grande ampleur est lancée au Chili en 1982 durant la dictature et une loi constitutionnelle est votée, la LOCE (Ley Orgánica Constitucional de Enseñanza), en mars 1990. Cette loi modifie en profondeur le système éducatif dans ses structures et son financement :

- décentralisation avec le transfert des responsabilités et des moyens aux municipalités ;

- mise en place de trois types d'écoles : l'école publique dite école municipale, l'école privée subventionnée (escuela particular subvencionada) et l'école privée (escuela particular pagado) ;

- perte du statut de fonctionnaire pour les enseignants.

3 Parallèlement, un système universel de bons d'études est mis en place afin de permettre à tous les élèves de s'inscrire dans une école privée ou publique; une allocation mensuelle proportionnelle au nombre d'inscriptions est accordée à ces écoles. Entre 1981 et 1996, le taux des inscriptions dans le secteur privé passe de $15 \%$ à 
$33 \%$ de la population scolaire totale ${ }^{1}$. En 2004 , il existe $54 \%$ d'écoles publiques, 37,8 \% d'écoles privées subventionnées et 7,6 \% d'écoles privées.

4 Lors du retour à la démocratie en 1990, la décentralisation décidée en 1982 est maintenue même si elle est partiellement remise en cause pour les premières années d'apprentissage considérées comme celles où les inégalités se mettent en place. Un programme appelé "programme des 900 écoles» est lancé en 1990 pour pallier les discriminations sociales entrainées par ce système à trois vitesses: il s'agit d'un programme d'amélioration de la qualité et de l'équité de l'éducation pré-scolaire et primaire des écoles situées dans des zones défavorisées ; ce même type de programmes est appliqué en 1995 au secteur secondaire.

En 2003, l'enseignement primaire (huit années) et secondaire (quatre années) devient gratuit et obligatoire par une révision de la Constitution.

6 Aujourd'hui, l'accès à l'éducation pré-scolaire reste assez bas pour les enfants les plus pauvres $(30,3 \%)$ mais le taux de scolarisation de cette même population s'est grandement amélioré au niveau de l'enseignement secondaire (de 73,3\% à 87,5\%, entre 1990 et 2003).

\section{L'enseignement supérieur en plein développement}

7 Le développement de l'enseignement supérieur au Chili a également connu un très grand accroissement durant la dernière décennie; de 1990 à 2001, le taux d'augmentation des inscriptions à l'université a été de 6,3\% par an. Mais les disparités sociales sont les plus grandes à ce niveau et l'accès à l'enseignement supérieur reste très difficile pour les classes défavorisées.

\section{Une grande diversité d'établissements}

8 Vers la fin des années quatre-vingts, l'enseignement supérieur se transforme dans ses structures. La loi sur l'éducation (LOCE) définit un cadre juridique qui permet la création d'établissements post-secondaires privés. Sur un total de 229 établissements, la répartition se fait entre universités (seize universités d'État, neuf universités privées subventionnées et trente-sept privées sans financement public), instituts professionnels et centres de formation technique. Cette diversité de l'offre éducative a des conséquences positives en termes d'effectifs. Le nombre des inscriptions qui atteignait 150000 en 1980 est passé, en 2002, à 500 000. Durant cette même période, le pourcentage des jeunes (18-24 ans) scolarisés dans des établissements d'enseignement supérieur est passé de $12 \%$ à $31,5 \%$ mais seuls $8,1 \%$ d'entre eux proviennent de la frange sociale la plus démunie. Pour élargir l'accès des jeunes issus de milieux modestes, il existe des aides et des bourses : les crédits proposés aux étudiants sont accompagnés de taux bonifiés, le montant du remboursement est fonction du revenu ultérieur et une franchise est accordée pendant deux ans après l'obtention du diplôme. En août 2005, un programme de bourses au mérite pour financer les études universitaires est mis sur pied. 


\section{Un climat général de revendications}

9 L'aide de l'État à l'enseignement supérieur a doublé depuis 1990 avec de très fortes progressions pour les aides accordées aux étudiants à revenu modeste et des fonds (fondos concursables) utilisés pour améliorer la qualité de l'enseignement. Selon une étude réalisée en 2006, $70 \%$ des étudiants qui intègrent l'université constituent la première génération de leur famille à accéder à l'enseignement supérieur. Pourtant, le conflit social majeur social qui a tenu le pays pendant plusieurs semaines a été le fait principalement des lycéens et des étudiants. Les revendications ont porté d'abord sur des points matériels : gratuité des transports pour les étudiants et gratuité de l'examen d'entrée à l'université pour s'élargir progressivement à une dénonciation d'un système d'éducation considéré comme très inégalitaire.

\section{Un plan de mesures}

10 Début juin, Michelle Bachelet a annoncé un plan de mesures qui répond en partie aux revendications exprimées par les manifestants. Les élèves d'origine modeste inscrits à des écoles subventionnées recevront des bourses ${ }^{2}$ pour l'examen d'entrée à l'université. Le nombre de rations alimentaires distribuées dans les écoles passera de 200000 à 300 000. Des travaux de rénovation seront conduits dans 520 lycées. Enfin, les droits d'inscription pour les élèves qui entrent en première année d'enseignement supérieur seront plafonnés en 2006. Un comité de conseil présidentiel (Consejo Asesor Presidential para la Calidad de la Educacion) a également été créé par Michelle Bachelet afin de préparer une réforme de l'Éducation nationale.

11 Mais ces mesures se sont révélées insuffisantes. Aux mois de septembre et d'octobre, le mouvement contestataire est entré dans une seconde phase avec des manifestations parfois violentes de lycéens et des occupations d'établissements. L'usure du mouvement lycéen et la signature d'un accord entre le gouvernement et les enseignants à la mi-octobre ont permis la sortie du conflit.

\section{Perspectives}

12 Ce conflit, d'une ampleur inégalée depuis le retour à la démocratie en 1990, traduit les inquiétudes profondes du pays pour son système éducatif. Le désengagement de l'État, la décentralisation et la privatisation, les trois principes clés de la réforme éducative instaurée par le régime de Pinochet ont été très fortement contestés par les mouvements sociaux de ces derniers mois et les revendications se sont cristallisées autour de deux notions: l'équité et la qualité. Une étude récente de l'OCDE sur le système éducatif chilien pointe ses faiblesses: formation initiale insuffisante des enseignants, forte inégalité d'accès à l'enseignement et plus particulièrement à l'université, et désengagement de l'État par une décentralisation excessive. Une nouvelle loi, destinée à remplacer la LOCE, doit être présentée au Parlement durant le premier semestre de l'année 2007 afin de modifier en profondeur le système éducatif, mais il sera difficile de répondre aux inquiétudes du pays et de limiter les faiblesses structurelles du système éducatif chilien. 


\section{NOTES}

1. C.R. Belfield \& H.M. Levin, La privatisation de l'éducation: causes effets et conséquences pour la planification, Paris : IIPE, 2003 (Principes de la planification de l'éducation).

2. 199907 pesos par mois (292 Euros).

INDEX

Mots-clés : enseignement supérieur, politique éducative, réforme de l'enseignement, système éducatif

Index géographique : Chili

\section{AUTEUR}

\section{BERNADETTE PLUMELLE}

Responsable du centre de ressources documentaires du CIEP 